it was shown that treatment of certain proteins, such as casein, with iodine under mildly alkaline conditions produced iodoproteins which exhibited thyroid activity by the oral route and from which thyroxine could be isolated after hydrolysis. Since iodocasein could be made quite readily from available materials it was evident that here was a cheap and plentiful supply of artificial thyroid hormone lending itself to easy administration to cows under practical conditions. Large-scale experiments carried out in this country under the aegis of the Agricultural Research Council and in the United States had shown that the galactopoietic effects observed with dried thyroid gland or thyroxine could be reproduced in all essentials by feeding iodoprotein. One important point was that prolonged feeding of doses sufficient to produce milk yield increases of the order of $30 \%$ above basal caused sufficient hypermetabolism to bring about significant and undesirable losses in body weight. If, however, one contented oneself with smaller responses the body weight losses were negligible, provided extra food was given in compensation. Clinical reports on the use of thyroid hormones for the stimulation of lactation in women had not always been favourable; in fact, some clinicians had advocated thyroid treatment for the suppression of unwanted milk secretion. Nevertheless, further clinical trials, keeping the necessity for careful control of dosage in mind, would appear to be justified.

\section{Vitamins in Human Milk}

Mrs. Mawson and Dr. S. K. Kon read a paper on the study of certain vitamins and other constituents of human milk. The investigation described had lasted for more than four years, during which period 2,000 samples of breast milk were examined. Owing to the food policy of the Government some of the changes they had noted had been for the better rather than the worse. They had taken Reading, a prosperous town in an agricultural area, as a starting-point in the early summer of 1941; and in April, 1942, they had obtained support from the Medical Research Council which had enabled them to extend their activities to Shoreditch, thus providing a good contrast. In both areas the husbands of many of the mothers were in the Armed Forces, but Shoreditch had been more subject to enemy attacks than Reading. As a result of the work done confidential reports were sent each year to the Medical Research Council, and from these had followed certain important changes in wartime diet. The difference, in the analysis of the milk was most noticeable immediately after the introduction of " national" wholemeal bread and also the first consignments of oranges to reach this country during the war.

Mr. BouRne mentioned that one of the difficulties that Dr. Kon and Mrs. Mawson had encountered had been to discover women who were sufficiently ill-nourished to provide a really substantial difference in dietary intake compared with those on normal feeding; but there had been one woman found who was grossly undernourished, and it would be interesting to learn what differences were found in the composition of the milk. He had noticed tables on the screen showing the differences between cow's milk and human milk, and he had seen elsewhere attempts to supplement the milk in order to give the child the theoretical optimum. He thought that all such treatment of the natural product was nonsense, and that the more the child had of the natural milk the better it would be. Dr. Kon, in reply, said that with regard to the woman who was grossly undernourished the composition of the milk had been found to be perfectly normal, and it was also found from milk samples in Belgium and Holland taken immediately after liberation that this was usual. They had had to revise their ideas of the effects of starvation and shortage of calories and essential foodstuffs. At such a low level life was geared down so that they could run satisfactorily with a less output of energy.

The Association of British Chemical Manufacturers has issued from 166, Piccadilly, London, W.1, the 1946 edition of its directory British Chemicals and their Manufacturers. During the war years the Government forbade publication of new editions and this is the first revision of the directory since 1939 . A copy will be sent gratis by the manager of the A.B.C.M. to any inquirer writing on business paper or giving other genuine indication of his being likely to put the directory to good use as a purchaser of chemicals.

\section{Correspondence}

\section{The Physiology of Vision}

SIR,-I have read with great interest the leading article (June 28, p. 932). There are two points which I would like to raise.

In the first place, my doubts concerning the validity of the three-colour theory do not rest entirely on research in which it was necessary to confine the stimulus to single cones or to small clusters of functionally identical cones. Thus one experiment requiring no apparatus, which can be performed by anyone in an ordinary room, consists of taking three little coloured test objects 5-mm. square each-a bright red, a bright green, and a lemon yellow. These are separately mounted in the middle of pieces of black paper about $20 \mathrm{~cm}$. square. If these are examined at a distance of perhaps 5 metres to 10 metres-this distance varies somewhat with the intensity of the light and the personal equation of the observer-it will be found that the yellow test object has altered to pale grey or white, whereas the red one and the green one have retained their colour, with hardly any observable alteration. Now, on the three-colour theory yellow is a mixture of red and green; therefore it would be expected that all the three test objects would undergo changes at about the same distance, but this they do not do. If this experiment be repeated with monochromatic lights produced by a spectroscope a similar result will be obtained.

This was the first experiment that shook my belief in the three-colour theory, to which I had always been a strong adherent.

The second comment concerns Dr. Willmer's book. The writer of the leading article considers that it supports the threecolour theory. A careful examination of this book shows, however, that this is not the case, for it describes an essentially dichromatic hypothesis. This is shown with great clearness if the figures illustrating chapters III and IV are examined. It is true that he states here and there in the book that the dichromatic hypothesis as it stands appears to be inadequate, and that some other factor must be involved of which no account has so far been taken ; but in every anse he follows it by some such statement as: "There is at least the possibility of overcoming the difficulty under consideration, without immediately assuming the existence of another distinct type of receptor." Thus nowhere in the book can one find anything to suggest that Dr. Willmer wishes to abandon entirely the dichromatic hypothesis which he advances in such detail.I am, etc.,

$$
\text { London, E.C.1. }
$$

H. HARTRIDGE.

\section{The "Costoclavicular Syndrome"}

SIR,-As co-author with Graham Weddell of a paper ${ }^{1}$ in which the term "costoclavicular compression" of the subclavian vessels was introduced to the literature, and which is one of the two papers. specially mentioned in the text of the recent article in your columns on the "costoclavicular syndrome" by Telford and Mottershead, ${ }^{2}$ may I be permitted to forward my comments? I trust you will forgive the delay, but the issue containing this paper has only recently arrived in this country.

Prof. Telford and Mr. Mottershead have rightly stressed that no one mechanical cause can explain all cases of pressure symptoms involving the neurovascular bundle at the base of the neck, and to this view I subscribe. They conclude that under certain circumstances costoclavicular compressions may occur, but in spite of an exceedingly rich experience of cervical rib syndromes they do not appear to have recognized a single example of costaclavicular compression, and consequently leave their readers with a feeling that the syndrome is mere supposition.

Compression of the subclavian artery between the clavicle and an unusually placed first rib has now been seen at operation by a number of observers ${ }^{3} s \circ$ besides ourselves. We described a case with vascular symptoms in which, at operation, proof was forthcoming that the subclavian artery was being compressed intermittently between the clavicle and the first rib, and in which symptoms disappeared completely after this costoclavicular compression had been corrected by removal of a segment of the rib. In addition 